\title{
The yeast on the grape berry surface influenced by climatic factors
}

\author{
Meiling Yao ${ }^{1, *}$, Fei Wang ${ }^{1}$, Elizaveta Breahna ${ }^{2}$, and Gheorghe Arpentin ${ }^{2}$ \\ ${ }^{1}$ Technical University of Moldova, Faculty of food industry, bd. Stefan cel Mare 168, Chisnau, \\ Republic of Moldova \\ ${ }^{2}$ National Office for Vine and Wine, st. Mitropolit Dosoftei 126, Chisinau, Republic Moldova
}

\begin{abstract}
Republic Moldova is a country with long history of winemaking. Understanding the microorganism on the grape surface is very important to the winemaking process, and it's also a national strategy of development of the wine industry. In this study, twenty seven samples from three regions and three vintages in Republic of Moldova were studied. The conventional microbiological methods combine with molecular methods (PCR-DGGE) have been used for study the quantity and the quality of microbes. The result show that the yeast population on the berries are variable in different vintages, and in the climatic factors, the Cool nigt index (CI) affect the yeast most. From the identification result, A.Pullulans and R.glutins are two culture which are easy to be found on the Moldova grapes. The autochthonous S.cerevisiae also been identified, but it shows a different results from different vintages.
\end{abstract}

\section{Introduction}

The wine quality and the characteristic are influenced by the microorganisms present in the fermentation process. ${ }^{[1]}$ The natural yeast not only plays an important role in the winemaking process, but also in the "terrior". The population and the diversity of natural yeast on the berry surface are shaped by many factors such as vintages, the location of the vineyard and the climate. ${ }^{[2]}$ Although, researchers have studied the relationship between microorganism on the grape and the climatic factors and the regional factors. ${ }^{[3]}$ But it's still not clear how these factors influence the diversity and the population of microorganism on the grapes.

In this study, the grape berries collected from three protected geographical indications (PGI) regions in Republic of Moldova, conventional microbiological methods combine with molecular methods (PCR-DGGE) have been used for study the quantity of microbes and identification.

\footnotetext{
* Corresponding author: meilingyao2019@gmail.com
} 


\section{Material and method}

\subsection{Samples}

Grape samples collected from several vineyards in three PGI in Republic of Moldova: PGI Codru (PGI C), PGI Valul lui Traian (hereafter referred as PGI VLT) and PGI Stefan Voda (hereafter referred as PGI SV). The sampling time is when the grapes reach the technological maturity in every year. For each sample, $1 \mathrm{~kg}$ berries are took, the whole sampling process took place in sterile condition. Eight commercial varieties which can represent the regional characteristic were studied: Feteasca neagră, Fetesca Albă and Sauvignon Blanc et al. (detail in Table 1)

Table1. Characteristics of samples.

\begin{tabular}{|c|c|c|c|c|}
\hline PGI name & $\begin{array}{c}\text { Coordinates } \\
\text { Sampling Place } \\
\end{array}$ & Variety & Vintage & Sample Code \\
\hline \multirow{9}{*}{$\begin{array}{c}\text { PGI } \\
\text { "Codru” }\end{array}$} & \multirow{3}{*}{$(\mathrm{E} 47.41, \mathrm{~N} 27.98)$} & \multirow{3}{*}{ Feteasca Neagra } & 2018 & FN_C_18 \\
\hline & & & 2019 & FN_C_19 \\
\hline & & & 2020 & FN_C_20 \\
\hline & \multirow{3}{*}{$(\mathrm{E} 47.06, \mathrm{~N} 28.51)$} & \multirow{3}{*}{ Feteasca Alba } & 2018 & BG_C_18 \\
\hline & & & 2019 & BG_C_19 \\
\hline & & & 2020 & BG_C_20 \\
\hline & \multirow{3}{*}{$(\mathrm{E} 47.22, \mathrm{~N} 28.52)$} & \multirow{3}{*}{ Sauvignon Blanc } & 2018 & SA_C_18 \\
\hline & & & 2019 & SA_C_19 \\
\hline & & & 2020 & SA_C_20 \\
\hline \multirow{9}{*}{$\begin{array}{c}\text { PGI } \\
\text { "Valul lui } \\
\text { Traian" }\end{array}$} & \multirow{3}{*}{$(\mathrm{E} 46.39, \mathrm{~N} 28.73)$} & \multirow{3}{*}{ Feteasca Neagra } & 2018 & FN_VLT_18 \\
\hline & & & 2019 & FN_VLT_19 \\
\hline & & & 2020 & FN_VLT_20 \\
\hline & \multirow{3}{*}{$(\mathrm{E} 46.19, \mathrm{~N} 28.63)$} & \multirow{3}{*}{ Feteasca Alba } & 2018 & BG_VLT_18 \\
\hline & & & 2019 & BG_VLT_19 \\
\hline & & & 2020 & BG_VLT_20 \\
\hline & \multirow{3}{*}{$(\mathrm{E} 45.65, \mathrm{~N} 28.47)$} & \multirow{3}{*}{ Merlot } & 2018 & ME_VLT_18 \\
\hline & & & 2019 & ME_VLT_19 \\
\hline & & & 2020 & ME_VLT_20 \\
\hline \multirow{2}{*}{$\begin{array}{c}\text { PGI } \\
\text { "Stefan Voda" }\end{array}$} & \multirow[t]{2}{*}{$(\mathrm{E} 46.53, \mathrm{~N} 29.87)$} & \multirow[t]{2}{*}{ Feteasca Neagra } & 2018 & FN_SV_18 \\
\hline & & & 2019 & FN_SV_19 \\
\hline
\end{tabular}




\begin{tabular}{|c|c|c|c|c|}
\hline & & 2020 & FN_SV_20 \\
\cline { 2 - 5 } & $(\mathrm{E} 46.48, \mathrm{~N} 29.94)$ & Carbernet Franc & 2018 & CF_SV_18 \\
\cline { 4 - 5 } & $(\mathrm{E} 46.48, \mathrm{~N} 29.94)$ & Pinot Noir & 2019 & PN_SV_19 \\
\cline { 4 - 5 } & & 2020 & PN_SV_20 \\
\cline { 4 - 5 } & $(\mathrm{E} 46.53, \mathrm{~N} 29.87)$ & Rara Neagra & 2018 & RN_SV_18 \\
\cline { 4 - 5 } & \multirow{2}{*}{$(\mathrm{E} 46.53, \mathrm{~N} 29.87)$} & Viorica & 2019 & VI_SV_19 \\
\cline { 3 - 5 } & & 2020 & VI_SV_20 \\
\hline
\end{tabular}

\subsection{The acquisition of data on climatic factors}

In this study three synthetic and complementary viticultural climatic indices are used: 1) Heliothermal Index (HI) which corresponds to Huglin's heliothermal index. 2)Cool night index (CI), an index works as thee indicator of night temperature conditions during maturation. 3) Dryness index (DI), which is an indicator of the level of presence-absence of dryness.

The CI is the minimum temperature in September, and the other two index values obtained from formula:

$$
H I=\sum_{01.04}^{30.09} \frac{\left[(T-10)+\left(T_{x}-10\right)\right]}{2} d
$$

where the $T$ is the average air temperature $\left({ }^{\circ} \mathrm{C}\right)$, Tx is the maximum air temperature $\left({ }^{\circ} \mathrm{C}\right.$ ), $d$ is the length of day coefficient.

$$
D I=W_{0}+P-T_{v}-E_{s}(01.04-01.10)
$$

$W_{0}$ is the estimated regional mean, usually the adopting value $200 \mathrm{~mm}$ is used. $P$ is the precipitation, $T_{v}$ and $E_{s}$ are calculated by potential evapotrasnpiration ${ }^{[4]}$.

The acquisition of primary climatic data: $T, T_{x}, P, E T P$ were performed using i-metheos resorts.

\subsection{The method of yeast quantity analysis}

Grapes were randomly collected, using ethanol sterilised shears (100 berries). $300 \mathrm{~g}$ of berries were placed in a sterile $500 \mathrm{~mL}$ flask containing an isotonic peptone solution $(10 \mathrm{~g} / \mathrm{L}$ Bacto Soytone, $2 \mathrm{~mL} / \mathrm{L}$ of Tween 80 ) to wash for 3 hours at $30{ }^{\circ} \mathrm{C}$. The samples and dilution series was plated out on yeast peptone glucose plate (yeast extrac $10 \mathrm{~g} / \mathrm{L}$, Bactotryptone $10 \mathrm{~g} / \mathrm{L}$, glucose $20 \mathrm{~g} / \mathrm{L}$, agar $25 \mathrm{~g} / \mathrm{L}, \mathrm{pH}$ adjusted to 5.0 using orthophosphroc acid), at 25 incubation 10 days.The numeration was made on plates. The population of yeast was obtained from the formula:

$$
C F U / \text { berry }=\frac{C \times V \times m}{M}
$$

where, $C$ is the number of colony forming units (CFU) per $\mathrm{mL}, V$ is The volume of the dilution, $m$ ishe average weight of the berries, $M$ is total weight of the berries. 


\subsection{The method of yeast quality analysis}

Amplification and sequencing were performed as described previously for analysis of yeast. ${ }^{[5]}$ Briefly, the D1 region of 26 rRNA gene was amplified by PCR using the primer NL1-GC (5'-GCG GGC GCG ACC GCC GGG ACG CGC GAG CCG GCG GCG GGC CAT ATC AAT AAG CGG AGG AAA AG-3') and primer LS2 (5' -ATT CCC AAA CAA CTC GAC TC-3'). PCR was run in a final volume of $50 \mu \mathrm{L}$ containing $0.5 \mu \mathrm{M}$ of each primer, $4 \mu \mathrm{L}$ of commercial mix (Invitrogen) and $2 \mu \mathrm{L}$ of DNA. The amplification was carried out as condition : $95^{\circ} \mathrm{C}$ for $5 \mathrm{~min}, 40$ cycles of $95^{\circ} \mathrm{C}$ for $1 \mathrm{~min}, 52^{\circ} \mathrm{C}$ for $45 \mathrm{~s}$ and $72^{\circ} \mathrm{C}$ for $1 \mathrm{~min}$, and final $72^{\circ} \mathrm{C}$ for $7 \mathrm{~min} .5 \mu \mathrm{L}$ aliquot of the amplified DNA was analysed by $1.5 \%$ agarose gel electrophoresis to verify that the PCR worked prior to DGGE. The DGGE separation was performed on a BIO-RAD DGGE system.

\subsection{Statistical analysis}

PCA analysis are used for studying the climatic factors. Graphics were made by R 4.04. Analysis of variance (ANOVA) was applied to the experimental data for the population analysis in different vintages and regions. The means were analysed using the $\mathrm{R} 4.04$. The significant differences were determined by the mean of one-way ANOVA, and the results were considered significant if the associated $\mathrm{P}$ values were $\leq 0.05$.

\section{Results and discussion}

\subsection{Quantity result}

In order to evaluate the influence of the regions and vintages, variety factors are ignored, the population of yeast (CFU/berry) is the average of three varieties in the same region and same vintage. Graphics were made by Origin 2018 Lab.

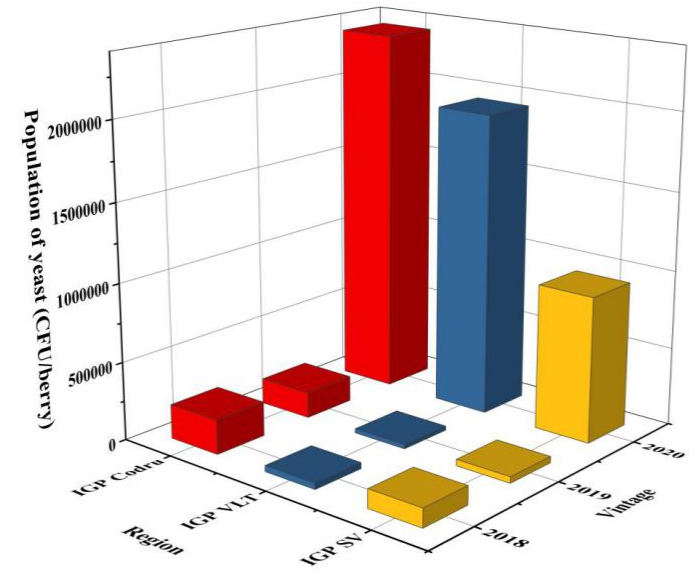

Fig. 1. The quantity of yeast in three regions in vintage2018, 2019 and 2020. ANOVA test for Vintages $(\mathrm{P}=0.00466)$, Regions $(\mathrm{P}=0.807)$

The Figure1. shows a comparison of population of yeast on the grape surface in different vintages and regions. It's clear that the geographical factors is not significant, but when it comes to vintage, the populations show a significant variation $(\mathrm{P}<0.05)$, especially 
the vintage 2020 the population of yeast reach a high level.

Table 2. The value of climatic index (data from ng.fieldclimate.com) and the result of yeast quantity.

\begin{tabular}{|c|c|c|c|c|c|}
\hline \multirow{2}{*}{$\begin{array}{l}\text { Sample } \\
\text { Code }\end{array}$} & \multirow{2}{*}{$\begin{array}{c}\text { The population } \\
\text { of yeast } \\
\text { (CFU/berry) }\end{array}$} & \multirow{2}{*}{$\begin{array}{c}\text { The average } \\
\text { population of yeast } \\
\text { (CFU/berry) }\end{array}$} & \multicolumn{3}{|c|}{ Climatic Index* } \\
\hline & & & $\begin{array}{c}\mathrm{HI} \\
\left({ }^{\circ} \mathrm{C} \cdot \text { day }\right)\end{array}$ & $\mathrm{CI}\left({ }^{\circ} \mathrm{C}\right)$ & $\mathrm{DI}(\mathrm{mm})$ \\
\hline FN_C_18 & $6.00 \mathrm{E}+04$ & \multirow{3}{*}{$2.20 \mathrm{E}+05$} & \multirow{3}{*}{2311.73} & \multirow{3}{*}{2.85} & \multirow{3}{*}{141.49} \\
\hline BG_C_18 & $3.00 \mathrm{E}+05$ & & & & \\
\hline SA_C_18 & $3.00 \mathrm{E}+05$ & & & & \\
\hline FN_C_19 & $3.30 \mathrm{E}+05$ & \multirow{3}{*}{$1.64 \mathrm{E}+05$} & \multirow{3}{*}{2100.12} & \multirow{3}{*}{4.13} & \multirow{3}{*}{176.01} \\
\hline BG_C_19 & $1.60 \mathrm{E}+05$ & & & & \\
\hline SA_C_19 & $2.80 \mathrm{E}+03$ & & & & \\
\hline FN_C_20 & $1.00 \mathrm{E}+06$ & \multirow{3}{*}{$2.33 \mathrm{E}+06$} & \multirow{3}{*}{2174.00} & \multirow{3}{*}{10.55} & \multirow{3}{*}{75.19} \\
\hline BG_C_20 & $5.00 \mathrm{E}+06$ & & & & \\
\hline SA_C_20 & $1.00 \mathrm{E}+06$ & & & & \\
\hline FN_VLT_18 & $1.00 \mathrm{E}+05$ & \multirow{3}{*}{$3.90 \mathrm{E}+04$} & \multirow{3}{*}{2659.16} & \multirow{3}{*}{-0.92} & \multirow{3}{*}{84.81} \\
\hline BG_VLT_18 & $9.70 \mathrm{E}+03$ & & & & \\
\hline ME_VLT_18 & $7.20 \mathrm{E}+03$ & & & & \\
\hline FN_VLT_19 & $1.70 \mathrm{E}+03$ & \multirow{3}{*}{$2.72 \mathrm{E}+04$} & \multirow{3}{*}{2479.39} & \multirow{3}{*}{1.14} & \multirow{3}{*}{43.42} \\
\hline BG_VLT_19 & $3.70 \mathrm{E}+04$ & & & & \\
\hline ME_VLT_19 & $4.30 \mathrm{E}+04$ & & & & \\
\hline FN_VLT_20 & $8.00 \mathrm{E}+05$ & \multirow{3}{*}{$1.93 \mathrm{E}+06$} & \multirow{3}{*}{2398.00} & \multirow{3}{*}{7.04} & \multirow{3}{*}{53.45} \\
\hline BG_VLT_20 & $1.00 \mathrm{E}+06$ & & & & \\
\hline ME_VLT_20 & $4.00 \mathrm{E}+06$ & & & & \\
\hline FN_SV_18 & $2.00 \mathrm{E}+05$ & \multirow{3}{*}{$1.20 \mathrm{E}+05$} & \multirow{3}{*}{2662.69} & \multirow{3}{*}{4.57} & \multirow{3}{*}{-56.57} \\
\hline CF_SV_18 & $6.00 \mathrm{E}+04$ & & & & \\
\hline RN_SV_18 & $1.00 \mathrm{E}+05$ & & & & \\
\hline FN_SV_19 & $1.90 \mathrm{E}+03$ & $4.08 \mathrm{E}+04$ & 2503.83 & 5.90 & -28.00 \\
\hline
\end{tabular}




\begin{tabular}{|c|c|c|c|c|c|}
\hline PN_SV_19 & $1.20 \mathrm{E}+05$ & & & \\
\cline { 1 - 2 } VI_SV_19 & $4.10 \mathrm{E}+02$ & & & \\
\cline { 1 - 2 } FN_SV_20 & $6.00 \mathrm{E}+05$ & & & & \\
\cline { 1 - 2 } PN_SV_20 & $2.00 \mathrm{E}+05$ & & \multirow{2}{*}{2292.41} & 8.80 & -28.90 \\
\cline { 1 - 2 } VI_SV_20 & $2.00 \mathrm{E}+06$ & & & & \\
\hline
\end{tabular}

* Data collected from the network of weather stations installed on the experimental plots (ng.fieldclimate.com)

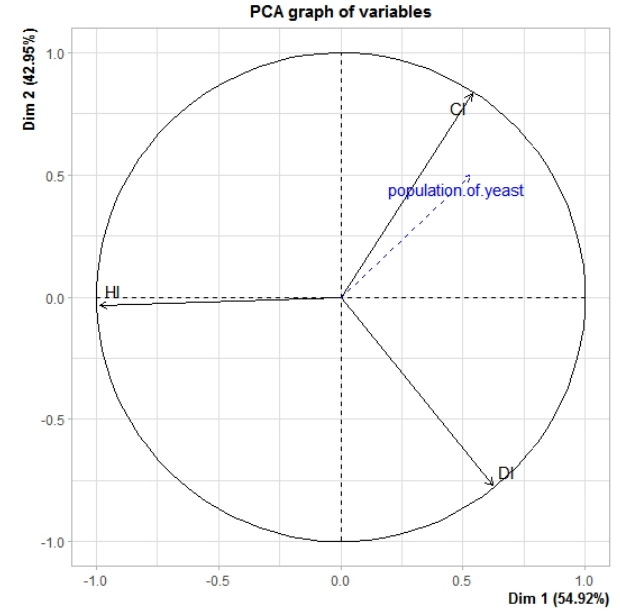

(a)

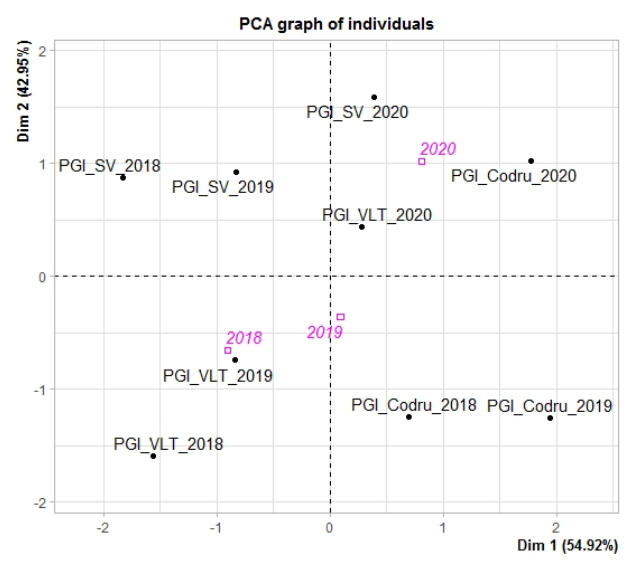

(b)

Fig. 2. The PCA result (a) the population of the yeast in three vintages and three region (b) the influence of climatic factors on grape yeast.

In Fig.2. (a) it can be observed: CI is the most influential factor on population of yeast, and the influence is positive. The HI has a negative influence on the population of yeast. When it comes to DI, it seems very little influence is.

Fig.2. (b) shows that vintage 2020 the population of yeast with a high level and the vintage 2018 and 2019 are close. In vintage 2020 the CI is bigger than other two vintages. However the vintage 2019 is drier, 2018 is warmer. In PGIs, the PGI SV is wetter, to the contrary, the PGI Codru is drier. And in the vintage 2018 and 2019 the PGI VLT with a low CI value.

Considering that $\mathrm{CI}$ is an indicator of night temperature conditions during maturation,. it can be speculated that the climatic factors in the maturation period or veraison are important to the microbes on grape berry, it should be studied in the future.

\subsection{Quality result}

Every year we chose to isolate 4 types of yeasts whose colonies presented interesting morphotypes. The result shows in Table 3. 
Table 3. The result of yeast quality on grapes in three vintages.

\begin{tabular}{|l|l|}
\hline 2018 Sequencing result & R.glutinis, M.pulcherrima, A.pullulans, H.uvarum \\
\hline 2019 Sequencing result & R.glutinis, R.Gramins, A.pullulans, S.cerevisiae \\
\hline 2020 Sequencing result & M.pulcherrima, S.cerevisiae, A.pullulans, R.glutinis \\
\hline
\end{tabular}

Among the identified microbial species, A.pullulans and R.glutins were observed in three years of continuous.

H.uvarum and M.pulcherrima which is often the main species found on grapes. Both of them frequently appears in spontaneous fermentation. Killer strains of H.uvarum species may inhibit the fermentation of S.cerevisiae. ${ }^{[6]}$ The M.pulcherrima is also supported by the expression of many extracellular activities, such as enhance the release of varietal aromatic compounds. M.pulcherrima has a respiratory metabolism that can help to lower ethanol content when used under aerobic conditions. ${ }^{[7]}$ In addition it shows good compatibility with S.cerevisiae in producing a low to medium acidity and, function of reducing level of $\mathrm{H}_{2} \mathrm{~S}$. R.glutins is a specie with high adaptive capacity against environmental changes. ${ }^{[8]}$ It can explained that why the R.gulutins can be observed in all vintages studied.

In every vintage, S.cerevisiae straines are isolated to study, the FIG.3. is the comparison of genetic profile in three vintages.



Fig. 3. Genetic profile in vintage 2018, 2019, 2020.

It's clear that the S.cerevisiae strains in different vintage are totally different. All these strains are put in collection (freezer at $-80^{\circ} \mathrm{C}$ ) to proceed to further analysis. 


\section{Conclusion}

In the past three years, the population yeast on Moldova grapes with a annual variation, in which 2020 the population is highest. In the climatic factors, the influence of CI is most obviously, and the DI and HI have negative influence. A.Pullulans and R.glutins are two culture which are easy to be found on the Moldova grapes. The autochthonous S.cerevisiae found from grapes are totally different among different vintages.

\section{Acknowledgments}

This research under the support of the National Office for Vine and Wine of Republic Moldova (ONVV).

\section{References}

1. R.M. Callejona, A. Clavijob, P. Ortigueirac, A.M. Troncosoa, P. Panequeb, M.L. Moralesc, Anal. Chim. Acta, 660, 68-75 (2010)

2. A. Barata, M. Malfeito-Ferreira, V. Loureiro, Int. J. Food Microbiol. 153, 243-259 (2012)

3. N. Bokulich, T. Collins, C. Masarweh, G. Allen, H. Heymann, S. Ebeler, D. Mills, Mbio, 7(3),e00631-16 (2016) doi: 10.1128/mBio.00631-16

4. J. Tonietto, A. Carbonneau, Agric For Meteorol. 124,81-97 (2004)

5. V. Renouf, O. Claisse, et al. Aust. J. Grappe Wine Res., 11, 316-327 (2005)

6. F. Radler, M.J. Schimit, B. Meyer, Arch. Microbiol., 154, 175-178 (1990)

7. A. Morata, I. Loira, C.Escott, J. Fresco, M. Banuelos, J. Suarez-Lepe, Fermentation, 5(3), 63 (2019)

8. E. Longo, J. Cansado, D. Agrelo, T.G. Villa, Am. J. Enol. Vitic., 42, 141-144 (1991) 